\title{
Resilience Pathways Against Poverty and Extremism: Framing Public Issues Within State Policy and Community Action
}

\author{
Narelle Wilson \\ Bachelor of Arts \\ Murdoch University \\ Perth, Australia \\ narellespygirl777@gmail.com
}

\author{
Pius Suratman Kartasasmita \\ Department of Public Administration \\ Parahyangan Catholic University \\ line 3-City, Country \\ pius@home.unpar.ac.id
}

\begin{abstract}
The aim of this paper is to highlight that the consequences of poverty and inequality, which are not only represented in terms of wealth, but relates to equal opportunity and access to primary public services such as education, health, and employment. These are crucial public issues and sustainable development goals which requires government policy reforms and an approach from the community to incorporate collective action. As a result of academic literature and research reviews, this paper argues that when sectors of society are excluded and disengaged from access to education, health services and employment, or deprived of opportunity of future prosperity, they may use extremist violence or terrorism to vent the political frustrations in current policy and their feelings of social discontentment. The emergence of extremist violence and terrorism as structural social violence in a society may be present due to poor policy and a lack of social cohesion. Effective policies and resilience programs are most successful when the community can take ownership of the policy reforms on the public issues directly affecting their community, and this inadvertently can achieve even broader global outcomes. However, this also requires good governance which introduces policies that provide violence reduction initiatives through employment, vocational and education programs, in conjunction with poverty and inequality alleviation in the most vulnerable communities. It is hypothesised that having proactive policy reforms can cultivate individuals and entire communities into a culture of resilience which encourages collective community action as a pathway out of poverty, inequality, extremist violence and terrorism. However, this requires government fundinginto sustainable development programs, initiatives and the political will for policy reforms.
\end{abstract}

Keywords-resilience, inequality, poverty, violent extremism, terrorism, policy reforms

\section{INTRODUCTION}

The focus of this article is human security encompassing poverty and inequality, and terrorist related social violence. It has beenascertained as being prevalent among the impoverished and deprived sectors of society, where the discontentment that arises from the inequality emerges as social violence, such as extremist violence and terrorism. The paper aims to substantiate the claim that economic deprivation, experienced through inequality, unemployment and suffering abject poverty, can be a root cause contributing to urban crime and extremist violence, often emerging as political violence in Indonesia. However, these findings are not confined to one location, as extremist violence and terrorism are on the global rise. The paper takes an interdisciplinary approach in suggest that initiating sustainable development and community programs aimed at education, employment, economic empowerment and poverty alleviation. This can be partially achieved through policy reforms, and funded programs thatevolve individual resilience and ultimately bring about social change through collective action. Firstly, the paper will discuss the public issues of human security, such as poverty, inequality, inadequate education services and the lack of employment opportunities, which can trigger many social problems for the individual, but also inevitably society. Societal problems such as urban crime and violence are higher in communities affected by abject poverty and amongst those unemployed and/or uneducated (Bhatia, Kartika and Ghanem 2017: 3). Secondly, to examine the potential risk factors that are thought to lead to the behaviour of extremist violence and terrorism, which includes a range of problems from sociological motivation from discontentment, psychological conditions, ideology/belief and values, political grievances, and economic factors (Mirahmadi 2016: 132). By having an understanding of these risk factors the paper suggests that community action along with developing an individual's resilience to extremist violence and terrorism, it is possible to change the path of those who are most at risk and vulnerable, through preventative proactive action. Lastly, the paper proposes that policy reform is required by governments to instigate positive changes at a grassroots level within the communities most affected in order to prevent extremist violence and terrorism. The Strategic Analysis Framework (Noll-Bales: 1999) is proposed as a tool to develop and implement policies addressing the causal links between, poverty, social structural violence and the human insecurity, and that of political and extremism violence and terrorism. The thesis of the paper is that by providing pathways in resilience against poverty, inequality and extremism, this gives individuals and their communities ownership of the public issues. Therefore, incorporating government initiatives and sustainable development programs, through reforms in human security development policythe collective community action 
could effectively become the tools of counter-terrorism and build resilience against extremist violence and terrorism.

\section{ROOT CAUSES OF SOCIAL VIOLENCEVIEWED AS EXTREMIST VIOLENCE AND TERRORISM}

More recent research has often disputed previous claims that poverty and a lack of education were causal links to terrorism, however, they remain important factors to take into consideration when understanding the drivers of extremist violence and terrorism. It has emerged in research that poverty and a low level of education affect different societies according to the demographics of that particular environment, which extends to the differing region's ideology, be it religious or political, or violence may arise due to civil society conflict and economic instability (Zaidi 2010: 400-1). This is also true of poverty indicators depending on whether it is referring to urban or rural poverty. Social behaviour such as extremist violence has been seen to soar in the rural regions of Pakistan for example, where abject poverty has made the acquisition of land for subsistence agriculture impossible. This is different for urban poor in Pakistan where the motivation for social violence is the disparity between incomes, or as Zaidi (2010) notes "the haves" and "the have nots" (Zaidi 2010: 402). It can be seen that differing demographic factors can motivate individuals towards extremist violence or terrorism, and is determined by a combination of events and circumstances that should be studied on a sub-national level, not on an international level (Zaidi 2010: 401). However, from the perspectives of the cultural, political and socio-economic, it is these variables which could actually be the one thing that the differing demographics can all relate to. That is, it is the experienced deprivationwhich is the one condition of social levelling that they all can relate to. That is, that despite their diversity and geography, those who are affected by poverty, inequality and the economics which constrain their hopes of prosperity and that their life expectations not going to become a reality. These are deemedroot causes that become motivators and should be considered as important triggersof escalating social discontentment which has been seen to result in extremist violence and terrorism.

It is at this point that this paper will add some clarification to the terms of extremist violence and terrorism. It is widely known that when attempting to define these terms there is no universally accepted definition or international consensus on a definition for such a complex geo-political, social and psychological phenomenon. However, many academics and organisations have attempted to succinctly describe these terminologies.

The Australian Government describes violent extremism as; "Violent extremism is the beliefs and actions of people who support or use violence to achieve ideological, religious or political goals. This includes terrorism and other forms of politically motivated and communal violence. All forms of violent extremism seek change through fear and intimidation rather than through peaceful means. If a person or group decides that fear, terror and violence are justified to achieve ideological, political or social change, and then acts accordingly, this is violent extremism."(Australian Government:2017)
This then leads to the question of how is terrorism defined. A definition is provided below from authors Lutz and Lutz (2005); "Terrorism involves political objectives and goals. It relies on violence or the threat of violence. It is designed to generate fear in a target audience that extends beyond the immediate victims of the violence. The violence involves an organization and not isolated individuals. Terrorism involves a non-state actor or actors as the perpetrator of the violence, the victims, or both. Finally, terrorism is violence that is designed to create power in situations in which power has previously been lacking (i.e., the violence attempts to enhance the power base of the organization undertaking the action)" (Lutz and Lutz 2005: 7).

This definition is provided by well-renowned scholars in the field of terrorism, however, other scholars also note that the state, as well as non-state actors, have been guilty of terrorism. It is argued that terrorism is a problem of the state as much as terrorism is a force used against the state (Hoffman: 2002). Hoffman (2002) explains this by stating that people may take a pathway to terrorism when they '...cannot change places', that is to say that although we are all different, and society will always remain that way, yet if the differences become the reason for the division, then this can arise as frustration and repression by the states (Hoffman: 2002). These divisions in society are often seen as a result of not being able to be overcome the repression. Therefore, the repressed groups sense that there is no realistic exit strategy from their adverse suffering due to the huge disparity in wealth, a lack of religious intolerance, societal resentment and deprivation. Hoffman (2002), describes this as the 'blame' ideology, which may developand from which point terrorism can evolve (Hoffman: 2002). It is for this reason that it is postulated that in order to diminish orlessen terrorism, the policies that are required to be implemented must address the terrorists' frustration and desperation that lead them on this pathway. Therefore, the discussion leads back to societal issues where the people feel driven to violent extremism as a way of trying to overcome their differences, discontentment and societal divisions, which in turn can also destroy the everyday way of life for the wider public. It is also due to these complex social processes that the bitterness and hatred is directed towards the terrorist groups who rebel against the government. But, it is also the terrorists themselves who have the same attitude towards the state institutions who are not proactive in resolving the differences and inequality that initially bred this violence. Hoffman (2002), makes an insightful statement when he notes that "The state is itself a terrorist which uses terror against terrorists" (Hoffman: 2002). When differences and inequality are not addressed by the state, such as religious intolerance, poverty, political frustrations and deprivation, it breeds a sense of total powerlessness and hopelessness within societal groups.Then no policy will succeed in reducing extremist violence or terrorism, not without policy reform and good governance.

\section{LOCAL AND GLOBAL RISE OF EXTREMIST VIOLENCE AND TERRORISM}

The situation of inequality and poverty is prevalent throughout Indonesia, and possibly most predominant in 
Jakarta. Jakarta has an extremely high population density of twelve million people, and for many, they make up the majority of people living in low socio-economic and impoverished conditions. This makes Jakarta an interesting case to study when examining the causes of social, political and extremist violence, including terrorism. The inequality in Jakarta has been documented in the OXFAM 2017 Report, stating that "The four richest men in Indonesia now have more wealth than the poorest 100 million people. Inequality is slowing down poverty reduction, dampening economic growth and threatening social cohesion" (Oxfam 2017: 1). The World Bank has set the 'moderate' poverty line at $\$ 3.10$ a day, which therefore means this represents a figure of 93 million people in Indonesia or 36 percent of the population. The Oxfam Report (2017) suggests that a large number of Indonesians are living just above this 'moderate' poverty line and therefore they are extremely vulnerable to falling down the scale and back into poverty. Perhaps one of the most telling signs from the Oxfam Report (2017) is that Southeast Asia (SEA), more than any other country or region, has climbed upwards in the last twenty years to attain an unenviable status. Stating that SEA has risen the fastest in the gap between the richest and the rest, placing Indonesia on the list of having the sixth worst degree of inequality of wealth in the world, this is a revealing statistic (OXFAM 2017: 2). It is this inequality and disparity that often breeds discontentment and frustration among the society, and particularly towards the political systems. It is important to note that not all inequality is measured by wealth, as much inequality is seen in unequal opportunity and unequal access to services such as health, education and employment, and as the Oxfam Report (2017) notes, inequality is about power. Power to those who get to make the rules and make the decisions, and who get to change the status quo, or not (Oxfam 2017: 8-9). More recent qualitative research studies have been able to establish that inequality becomes a mobilising agent when it is socially-embedded (Mancini 2005: 6-7). These findings confirm that where relative deprivation is present, it forms the precondition for civil conflict in a society. The deprivation may be of variable type, but basically described as where the differences are cultural and where the vast inequalities exist in political opportunities, social access, economic assets, employment and income (Mancini 2005:6). These differences give rise to everyday violence, political violence and ethnic violence, and is particularly prevalent where the wealthyelites lifestyles are set against a backdrop of extreme poverty, and can be seen to threaten the social cohesion, (Oxfam 2017:11). This is very prominent throughout Indonesia, and especially when the few rich and privileged cause a power imbalance where the poor have very little, if any, say in political processes or any of the country's economic policies. The social discontent rises as the small group of wealthy elites continue to benefit from government policies and economic outcomes, and the great number of low socio-economic population do not have their basic societal requirements met.

\section{Community ACtion, Resilience And StRATEgIC Frame ANALYSIS APPROACH}

It is proposed that the government of Indonesia reforms policy and increases the budget allocation to programs that promote equality and resilience, such as equitable access to vocational skills and training, and to formal education. This applies in particular for those from a low socio-economic background, with the aim of closing the gap between the rich and the rest (Oxfam Report 2017: 35). By framing extremist violence and terrorism as public issues, it enables and integrates the power of communication and the influence of media towards public issues, especially when public support for programs and policies are required. Much the same way as the violent extremists and terrorists also rely on the media as its powerful communication forum. Therefore, it is beneficial to approach such public issues using the strategic framework analysis (SFA) concept. Using this interdisciplinary format provides a framework which incorporates an anthropological, political science and sociological perspective. By forming community action groups and resilience programs based on policies using the four functions of the SFA, which are research, learning, public presentation and interpretation, this brings together the essential ingredients to formulate successful sustainable develop programs for communities. By combining these theories, functions and research methods, from both the cognitive and social sciences, it is then important to investigate how the public views issues, and whether program implementation will be supported by community action (NollsBales:1999). It is proposed that using a SFA model is a more successful way for governments to communicate to the public about specific social issues, and to aim for more successful outcomes of community and development programs once they are implemented (Nolls-Bales: 1999). This was found to be the case because this framework built both public will and a greater public understanding of the social issues, which do not only affect the individual, but the entire community. The SFA approach means that when the public is well informed and involved, and where the government is given a clear role it is required to play, then public issues has been placed squarely in the centre of the target. The Indonesian legislative assembly speaker Zulkifli Hasan is quoted as saying "Our main enemy is inequality" (Lu: 2017). He also stated that "Social justice should be for all citizens, not just a few" (Lu: 2017). This view is supported by the current Indonesian President, Joko Widodo, who stated that his top priority is to narrow the wealth inequality gap (Lu: 2017). In Mancini's (2005) research he found that "Inequality becomes a mobilising agent when it is socially-embedded: poor and rich are not only separated by their money, but also by their culture, language or appearance" (Mancini 2005: 6-7). This is very important for governments to understand and consider in their policy making and their aims to reach sustainable development goals.

\section{CONCLUSION}

In conclusion, current research highlights that where there are high levels of poverty, inequality and relative deprivation which inhibits any hope of prosperity and political inclusion, this breeds a tremendously high risk level of discontentment amongst a society. Thissequentially has been seen to emerge as social violence in the form of extremist violence and is often a pathway to terrorism. The essay found that the more severe the poverty, inequality and discontentment, the more likely there will be extremist violence existing in a society. The inequality was seen in wealth, economics, politics, access to public services such as health and education, and a deprivation of 
employment opportunities. It is proposed that in order to overcome the inequality and the gaping disparity between those who have and the rest, that governments make a commitment to reform their policy making and implementations of policiesto address the issues of poverty and inequality. In addition, that community programs are proposed to assist in the building of strong and resilient communities which will abate the need for individuals to take the pathway of extremist violence and terrorism. As these forms civil conflict are in general an expression of political and societal suppression, and repression. The research shows that when inequality is socially embedded in a society, it becomes the powerful rallying agent arousing social discontentment, which evolves in a society where there is a gaping division between rich and poor. In a country such as Indonesia, the division can be accentuated by the vast diversity of cultures, religions, ethnicities and languages. Therefore, state policy should use an interdisciplinary approach to policymaking and community programs such as the strategic framework analysis concept, where this approach incorporates anthropology, political science and sociological perspectives to public issues. In Indonesia, it is now up to President Joko Widodo and his government to develop and implement nationwide sustainable development programs that demonstrate how he intends to target inequality reduction in order to reduce the likelihood of extremist violence and terrorism. If this outcome eventuates, it could become a framework to be used for broader, global counter-terrorism solutions.

\section{REFERENCES}

[1] Australian Government. 2017. "Living Safe Together". https://www.livingsafetogether.gov.au/aboutus/Pages/what-is-violentextremism.aspx

[2] Bhatia, Kartika and Hafez Ghanem. 2017. How do Education and Unemployment Affect Support for Violent Extremism? Washington: Brookings Institution Press. http://libproxy.murdoch.edu.au/login?url=http://search.proquest.com.lib proxy.murdoch.edu.au/docview/1884604684?accountid=12629.

[3] Hoffman, John. "Terrorism. (Concept)." Politics Review, Apr. 2002, p. 32+. General OneFile, go.galegroup.com.libproxy.murdoch.edu.au/ps/i.do?p=ITOF\&sw=w\&u $=$ murdoch $\& \mathrm{v}=2.1 \& \mathrm{it}=\mathrm{r} \& \mathrm{id}=\mathrm{GALE} \% 7 \mathrm{CA} 86470851 \&$ sid=summon\&asi $\mathrm{d}=\mathrm{c} 613060 \mathrm{da} 67 \mathrm{c} 8 \mathrm{e} 4 \mathrm{f} 09 \mathrm{~d} 3 \mathrm{fa} 98313 \mathrm{be} 687$. Accessed 7 May 2017.

[4] Lu, Joanne. 2017. "Indonesia resolves to tackle inequality in 2017". HumanOSphere Organisation. $5^{\text {th }}$ January, 2017.
[5] http://www.humanosphere.org/basics/2017/01/indonesia-resolvestackle-inequality-2017/

[6] Lutz, J., and Brenda J. Lutz. Terrorism, edited by J. Lutz, and Brenda J. Lutz, Palgrave Macmillan US, 2005. ProQuest Ebook Central, http://ebookcentral.proquest.com.libproxy.murdoch.edu.au/lib/murdoch/ detail.action?docID=308183.

[7] Mancini, Luca. 2005. "Horizontal Inequality and Communal Violence: Evidence from Indonesian Districts". Centre for Research on Inequality, Human Security and Ethnicity(CRISE). CRISE WORKING PAPER No. 22 November 2005. Queen Elizabeth House, University of Oxford.

[8] https://assets.publishing.service.gov.uk/media/57a08c6ded915d3cfd001 3aa/wp22.pdf

[9] Mirahmadi, Hedieh. 2016"Building Resilience against Violent Extremism". The ANNALS of the American Academy of Political and Social Science Vol 668, Issue 1, pp. 129 - 144. First published date: October-21-2016. $10.1177 / 0002716216671303$. http://libproxy.murdoch.edu.au/login?url=http://search.proquest.com.lib proxy.murdoch.edu.au/docview/1752130985?accountid=12629.

[10] Mirahmadi, Hedieh, Mehreen Farooq, And Waleed Zaid. May 2010. "WORDE World Organization for Resource Development and Education". 1875 Eye St NW Suite 500 Washington DC 20016. http://www.worde.org/wp-content/uploads/2010/12/WORDE-WhitePaper-Traditional-Muslim-Networks.pdf

[11] Nolls-Bales, Sussan. 1999. "Strategic Frame Analysis". Frameworks Institute. Frameworksinstitute.org.com http://www.frameworksinstitute.org/sfa-overview.html

[12] OXFAM. 2017. "Towards A More Equal Indonesia: How the government can take action to close the gap between the richest and the rest ". Oxfam Briefing Paper February 2017. https://www.oxfam.org/sites/www.oxfam.org/files/bp-towards-moreequal-indonesia-230217-en_0.pdf

[13] Zaidi, Syed Manzar Abbas. 2010. "The Poverty-Radicalisation Nexus in Pakistan".Global Crime, Vol:11(14), 2010. DOI: $10.1080 / 17440572.2010 .519521$

[14] http://dx.doi.org/10.1080/17440572.2010.519521

[15] Tadjoeddin, Mohammad Zulfan, and Syed Mansoob Murshed. "SocioEconomic Determinants of Everyday Violence in Indonesia: An Empirical Investigation of Javanese Districts, 1994-2003." Journal of $\begin{array}{llll}\text { Peace Research44, no. } 6 & \text { (2007): } & 689-709 .\end{array}$ http://www.jstor.org.libproxy.murdoch.edu.au/stable/27640595.

[16] Thomson, Alice. 2017. "Poverty to Blame for Extremism, Says Tory." The Times, Mar 25, 11.http://libproxy.murdoch.edu.au/login?url=http://search.proquest.com. libproxy.murdoch.edu.au/docview/1880695076?accountid=12629.

[17] Wilson, Ian. 2017. "Jakarta: inequality and the poverty of elite pluralism". New Mandala.

[18] 19 April, 2017. http://www.newmandala.org/jakarta-inequality-povertyelite-pluralism/ 